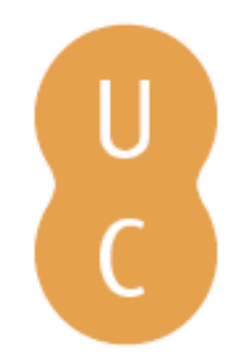

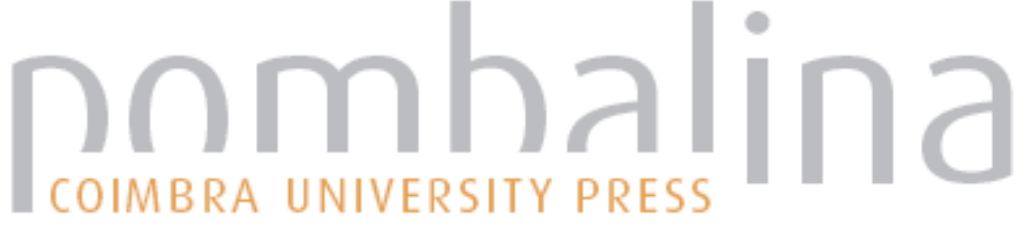

\section{Ao António Gama Mendes: os juvenis anos liceais}

Autor(es): $\quad$ Carvalho, Jorge M. R. F.

Publicado por: Imprensa da Universidade de Coimbra

URL

persistente: $\quad$ URI:http://hdl.handle.net/10316.2/43471

DOI: $\quad$ DOI:https://doi.org/10.14195/978-989-26-1343-7_1

Accessed : $\quad$ 26-Apr-2023 12:42:24

A navegação consulta e descarregamento dos títulos inseridos nas Bibliotecas Digitais UC Digitalis, UC Pombalina e UC Impactum, pressupõem a aceitação plena e sem reservas dos Termos e Condições de Uso destas Bibliotecas Digitais, disponíveis em https://digitalis.uc.pt/pt-pt/termos.

Conforme exposto nos referidos Termos e Condições de Uso, o descarregamento de títulos de acesso restrito requer uma licença válida de autorização devendo o utilizador aceder ao(s) documento(s) a partir de um endereço de IP da instituição detentora da supramencionada licença.

Ao utilizador é apenas permitido o descarregamento para uso pessoal, pelo que o emprego do(s) título(s) descarregado(s) para outro fim, designadamente comercial, carece de autorização do respetivo autor ou editor da obra.

Na medida em que todas as obras da UC Digitalis se encontram protegidas pelo Código do Direito de Autor e Direitos Conexos e demais legislação aplicável, toda a cópia, parcial ou total, deste documento, nos casos em que é legalmente admitida, deverá conter ou fazer-se acompanhar por este aviso. 


\section{FERNANDA CRAVIDÃO}

\section{IÚCIO CUNHA}

PAULA SANTANA

\section{NORBERTOSANTOS}

(ORG.)

\section{ESPAÇOS E TEMPOS EM GEOGRAFIA}

HOMENAGEM A ANTÓNIO GAMA

IMPRENISA DÁ UNIVERSIDADE DE COIMBRA COIMBRA UNIVERSITY PRESS

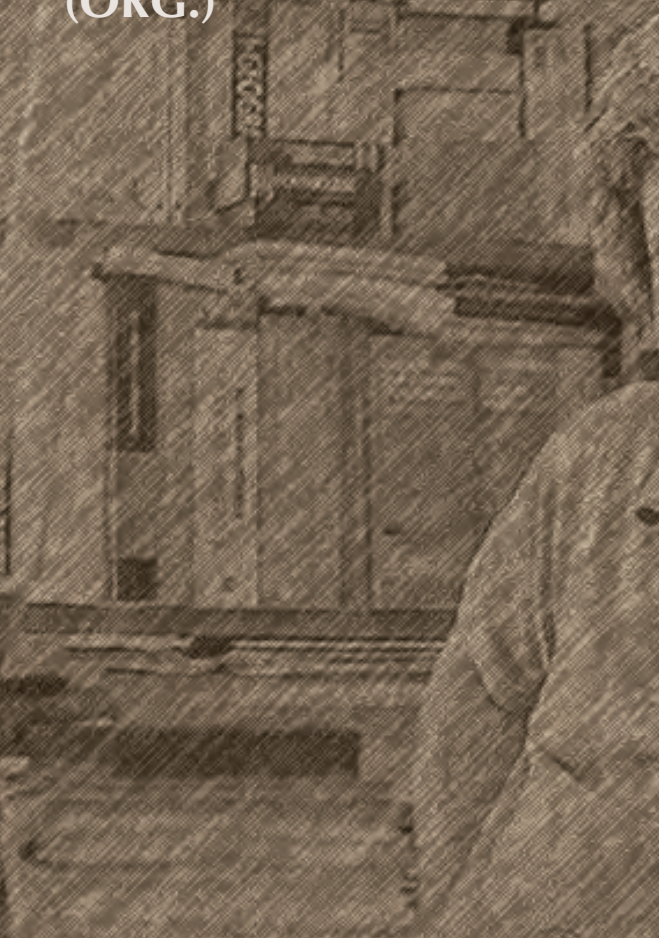




\section{Ao antónio gama mendes. OS JUVENIS ANOS LICEAIS}

Jorge M. R. F. Carvalho

Licenciado em Geografia. Professor da Escola Secundária José Falcão, Coimbra (aposentado)

Convidado a colaborar nesta homenagem a António Gama Mendes (Álvaro, concelho de Oleiros 30.12.1948 - Coimbra 31.12.2014), senti alguma hesitação pela responsabilidade de evocar reminiscências dos nossos anos liceais, já distantes no tempo; no entanto, a hesitação foi ultrapassada pelo sentido de obrigação em colaborar na homenagem a um colega, um cidadão, um amigo, com quem, ao longo de 50 anos, consolidei amizade e consideraçáo pessoal mútua.

Neste testemunho não serão feitas referências ao valioso e diversificado currículo académico e profissional do António Gama, outros o farão melhor e com mais pertinência. $\mathrm{O}$ presente testemunho evoca, de memória, apenas alguns retalhos do enquadramento escolar do nosso Liceu D. João III, em Coimbra, onde fomos contemporâneos na década de 60 e, em dois anos, colegas de turma, e de algumas vivências que tiveram como ator o António Gama.

Com a partida prematura do António Gama Mendes, resta a profunda saudade de um amigo, amável, bom conversador, sensível, capaz de fazer grandes amizades. Obrigado, Gama! Aqui fica o meu reconhecimento pela tua pessoa de grande riqueza humana e de cidadão sempre atento e disponível a participar no exercício dos direitos de cidadania. 


\section{$\mathrm{O}$ enquadramento escolar do nosso liceu}

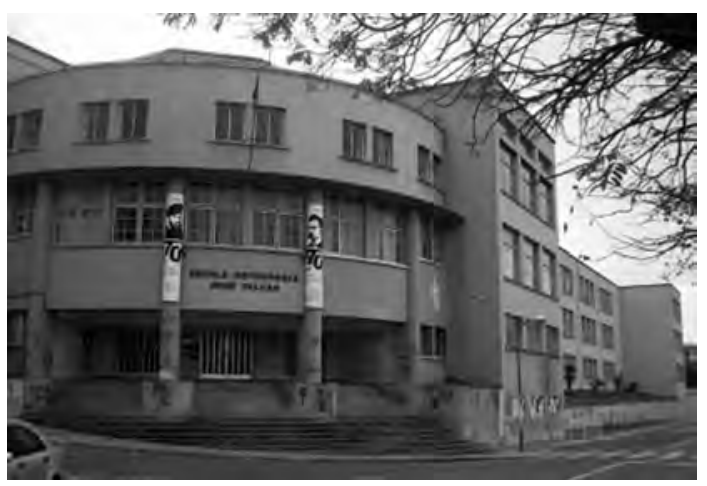

Figura 1

O plano de estudos do ensino liceal da época em que António Gama foi estudante liceal durava 7 anos, divididos em $10^{\circ}$ e $2 .^{\circ}$ ciclos (de carácter geral) e $3 .^{\circ}$ ciclo, designado por complementar, com várias alíneas de opçáo conforme o curso superior que o aluno pretendia seguir, e considerado como preparatório para os alunos prosseguirem estudos na Universidade, e no qual os estudantes deveriam aprender sólidos e vastos conhecimentos em cada uma das 6 disciplinas, consolidando uma boa formação, fundamentada nos princípios de uma educação nacionalista e cristã.

O ambiente no Liceu D. João III, tal como nos restantes do território nacional, era caracterizado pela ideologia dominante do Estado Novo, assente numa exigente disciplina, bem sentida pela presença e ação do Reitor, o Dr. Mário Guerra, uma verdadeira extensão do braço governamental junto dos alunos, professores e funcionários. O programa oficial de cada disciplina era extenso e com conteúdos bem difíceis e seletivos, que os exigentes professores procuravam cumprir na sua totalidade, tendo em vista que os alunos teriam de realizar provas de exame nacional no final do ciclo.

No nosso Liceu, no início dos anos 60, as turmas eram normalmente muito numerosas, por vezes com mais de 40 alunos, o corpo docente era constituído, na sua maioria, por professores muito experimentados, com muitos anos 
de docência e que durante as aulas cumpriam o programa oficial seguindo o manual da disciplina, à época, o livro único, normalmente de autoria de conceituados docentes.

\section{$\mathrm{O}$ jovem liceal}

António Manuel da Gama Mendes, conhecido e tratado no Liceu por colegas e professores por Gama, tinha chegado a Coimbra no ano letivo de 1962/63 para frequentar o 2. ${ }^{\circ}$ ciclo liceal, matriculando-se no Liceu Normal D. Joáo III, o único liceu masculino da cidade de Coimbra. Concluído o $2 .^{\circ}$ ciclo com a aprovação nos exames do $5 .^{\circ}$ ano (Secções de Letras e Ciências), o Gama matriculou-se, no ano letivo de 1965/66, no 6. ${ }^{\circ}$ ano, alínea C, onde fomos colegas de turma.

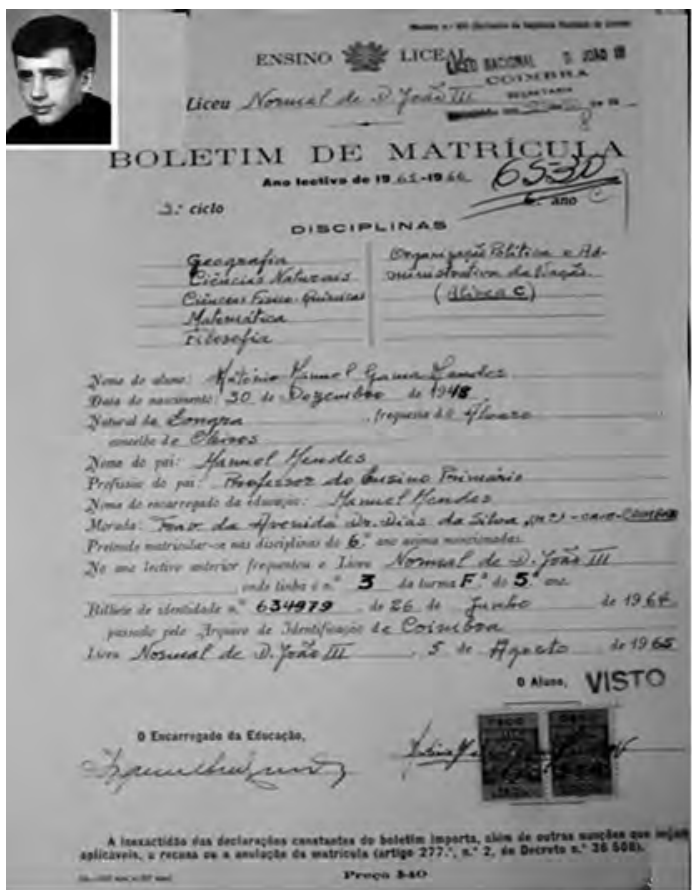

Figura 2 
O António Gama, julgo que o conheci em 1963, vindo das serranias de Álvaro, concelho de Oleiros, tal como outros rapazes provenientes do meio rural, perante o elevado número de alunos que frequentavam o Liceu e a responsabilidade de pertencer ao respeitado Liceu D. Joáo III, teve que vencer a natural timidez inicial, e cedo se integrou na vida académica, quer pela frequência das aulas, quer pela habitual visita à biblioteca do Liceu, quer nos intervalos e no final das aulas, nos jogos próprios da juvenil vivência.

A partir de 1965 a nossa proximidade cresceu, alicerçada no convívio quotidiano do ambiente turma, convivência que se transformou em amizade, talvez por ambos manifestarmos interesse comum por assuntos de índole geográfica. A nossa turma, o 6. ${ }^{\circ} \mathrm{B}$, constituía um grupo muito heterogéneo de 41 alunos, todos rapazes, matriculados na alínea A "Clássicas e Românicas", alínea B "Germânicas", alínea C "Ciências Geográficas", alínea D "Histórico-filosóficas”, alínea F "Ciências”, alínea G "Ciências Económicas e Financeiras" e alínea $\mathrm{H}$ "Arquitetura". Este grande grupo, ao longo dos tempos letivos de cada dia, fragmentava-se por diferentes salas, conforme as disciplinas comuns de cada alínea, apenas estando todos os alunos juntos nas aulas de Filosofia, OPAN e Educação Física, disciplinas comuns a todas as alíneas.

Nesse ano letivo de 1965/66 apenas 3 estudantes tinham procedido à sua matrícula no $6 .^{\circ}$ ano, alínea C, com destino ao curso superior de Geografia: o António Gama, o José Filipe Caetano e eu, o autor deste depoimento. Assim, naturalmente, se formou um pequeno grupo, o Gama, o Caetano e o Jorge que comungavam os mesmos propósitos de virem a ser professores de Geografia, o que, diga-se desde já, apenas dois concluíram essa caminhada, pois o José Filipe Caetano cedo escolheu outros caminhos profissionais.

O "nosso" Liceu, designado pela nomenclatura do MEN como Liceu Normal D. João III, desde a sua fundação, em 1936, a funcionar no atual edifício da Avenida Afonso Henriques, resultante da fusão do Liceu José Falcão e do Liceu Júlio Henriques, instalados no Colégio de S. Bento até 1936, desempenhava, à época e ainda na atualidade, a função de centro de formaçáa de professores, com excelentes e conceituados orientadores de estágio e metodólogos que preparavam e formavam centenas de professores estagiários que, após o exigente 
estágio, ficavam com habilitaçáo profissional que lhes permitia concorrer às escassas vagas de professores efetivos.

A referida turma do $6 .^{\circ} \mathrm{B}$ e a correspondente turma do ano seguinte tiveram como docentes de Geografia dois respeitados e competentes professores que também assumiam a responsabilidade de orientação de estágio, o Dr. Joáo de Medeiros Constância e o Dr. J. J. Ferreira Faustino que, temporariamente, substituiu o Dr. J. Medeiros durante o seu impedimento por obrigaçóes militares. Sendo estes os professores titulares da disciplina de Geografia, também orientadores de estágio, coube à referida turma, ser a turma de regências das aulas do curso complementar, onde os professores estagiários assumiam, periodicamente, a docência das aulas assistidas pelos seus orientadores. Assim, nestas circunstâncias, também foram docentes de Geografia na turma, as estagiárias Dr. ${ }^{a}$ Luísa Portela e Dr. ${ }^{a}$ Clara Ferreira.

Numa época de grande rigor disciplinar e exigência científica, estes docentes, cumprindo o programa oficial de Geografia do curso complementar, foram capazes de transmitir conceitos, conhecimentos científicos e hábitos de trabalho que, mais tarde, foram muito úteis na Faculdade. É bom recordar, agora no segundo decénio do século xxi, que o programa de Geografia do ensino complementar liceal, lecionado em 4 horas semanais, contemplava temas bem exigentes como Cosmografia, Geografia Física (essencialmente Climatologia e Geomorfologia), Biogeografia, Geografia Humana, e Geografia Económica, seguindo o modelo e conteúdos científicos da Escola Francesa de Geografia.

$\mathrm{O}$ método de ensino dominante naqueles tempos liceais era essencialmente expositivo, ministrado por bons professores, num espaço de sala de aula onde os alunos assumiam uma postura ordeira e disciplinada, procurando ouvir os professores e fazer os registos dos apontamentos considerados mais importantes.

A nossa turma tinha como docentes alguns professores considerados, pelos alunos, como "feras", como era o caso da Dr. ${ }^{a}$ Laura Mano (Matemática), Dr. Euclides Araújo (Físico-Químicas), Dr. Manuel Catarino (OPAN) e o Dr. Faustino (Geografia) com larga experiência docente em liceus nas colónias africanas. Com certeza ficaram na memória dos alunos as chamadas ao quadro na disciplina de Matemática, um autêntico calvário para quase todos os alunos, 
o Dr. Manuel Catarino (já nosso conhecido como professor de Português no $2 .^{\circ}$ ciclo), homem muito austero e exigente na memorização do articulado que fazia parte do programa de OPAN, o Dr. Euclides muito exuberante nas aulas; recordo o Dr. Faustino que nas aulas de "entrega e correção dos exercícios escritos" habitualmente expressava a sua rigorosa apreciação aos resultados de cada aluno de uma forma muito característica, vincadamente pessoal, por vezes, benevolente para os bons alunos, ora mais ríspido para os alunos com piores resultados. Era habitual "os ralhetes" individuais feitos perante toda a turma, a ameaça de escrever aos encarregados de educaçáo, criando nessas aulas um ambiente de ansiedade e evidente mal-estar na maior parte dos alunos. Ficou bem marcado na minha memória numa aula de "entrega e correção dos exercícios escritos" o referido professor, perante uma classificação aquém do esperado obtida pelo António Gama (tido como bom aluno), dirigir-lhe uma repreensão perante todos os colegas, que, em silêncio temeroso, iam ouvindo aquela severa apreciação que deixou o Gama mudo, com "as orelhas a arder" e o semblante rubro e crispado perante aqueles comentários contundentes, levando cada um dos restantes colegas a pensar, "se é assim com o Gama, o que será quando chegar a minha vez...”.

Julgo que, desde cedo, o Gama se interessou por curiosidades geográficas e gosto pelo conhecimento de outras paisagens distantes, pois com frequência escrevia postais às embaixadas e departamentos de turismo de outros países, solicitando o envio de revistas, guias turísticos e demais tipo de informação relativa a esses países.

O Gama sempre se revelou um bom companheiro, quer nas conversas de corredor e nos espaços de recreio, quer nas animadas futeboladas no pátio de terra batida do Liceu, onde, desde logo, foi evidente que as nossas perfomances com a bola ficavam muito longe dos nossos ídolos da época, o Eusébio do Benfica e o Rocha da Académica. Ainda no âmbito desportivo, lembro-me durante o ano letivo 1965/66 ou 1966/67, sendo eu já atleta praticante de atletismo na AAC, ter desafiado o Gama a ir treinar comigo ao Estádio Universitário, convite aceite por duas ou três vezes, não mais, pois a sua apetência de futuro atleta ficou por aí, não seguindo as pisadas do seu irmão Paulo que jogou hóquei em 
patins na AAC, foi dirigente desportivo, chegando, mais tarde, a Presidente da Direção da Federação Portuguesa de Patinagem. Apesar de não praticante, o Gama gostava de desporto, conhecia com pormenor algumas modalidades, gostava de discutir a atualidade desportiva e assistia na bancada a jornadas de eventos desportivos.

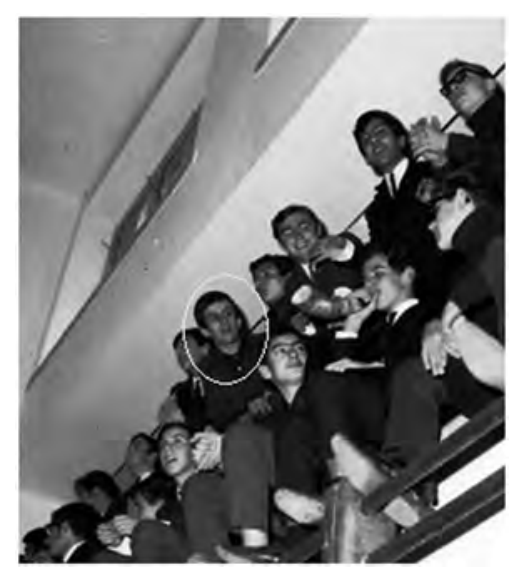

Figura 3

O António Gama foi assíduo frequentador da biblioteca do Liceu onde, algumas vezes estudámos juntos e onde era evidente a sua disponibilidade em ajudar os colegas, contribuindo para dissipar ou atenuar dúvidas evidenciadas em várias disciplinas, quer na realização dos "trabalhos de casa”, quer nos dias que antecediam os exigentes e temidos exercícios escritos, pois o seu resultado era determinante para a classificação no fim de cada período escolar e, portanto, da classificação final de cada disciplina. O António, a par do seu lado reservado, por vezes mesmo individualista, fazia com facilidade amigos, e usava com alguma frequência o traje académico de capa e batina, prática seguida por muitos alunos do Liceu, principalmente nos anos terminais do curso complementar. Esta prática da tradição académica está documentada na fotografia abaixo inserida, reportando o baile dos alunos finalistas de 1967 do Liceu D. João III, onde também participaram alunas finalistas do Liceu Infanta D. Maria. 


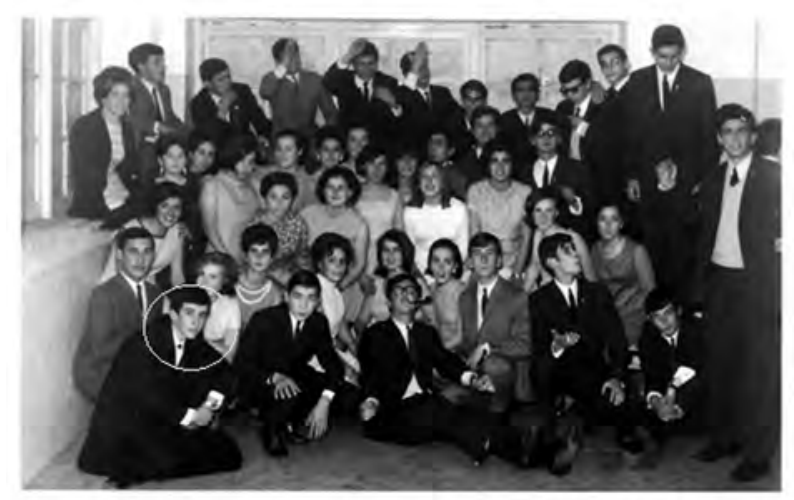

Figura 4

\section{Nota final}

$\mathrm{Na}$ presente evocação in memoriam a António Gama abordando tempos juvenis, incluo como complemento, outras evocaçóes mais tardias que constituem "momentos" que marcaram tempos em que privei com ele e que guardo com saudade:

i) a partilha de convívio de estudantes universitários e participação na crise académica de 1969;

ii) a disponibilidade e empenhamento do Gama como resposta ao meu convite para se deslocar ao Algarve, no início da década de 80, para participar numa ação de formação de professores onde apresentou o tema "A epistemologia da Nova Geografia";

iii) os nossos ocasionais encontros durante os quais conversámos sobre quase tudo, desde política local, nacional e internacional, futebol, os seus trabalhos em curso, a vida universitária. Quando esses encontros ocorriam ao sábado, o tema era sempre a edição semanal do Expresso, semanário que adquiria regularmente; 
iv) a participação em viagens de estudo também foi uma grata oportunidade para privar com o Gama, viagens em Portugal e em Espanha (a última com destino a Cáceres e Mérida) no âmbito da Ramo de Formação Educacional do Departamento de Geografia da UC, para as quais organizava rigorosos e utilíssimos guiōes de itinerários, sendo sempre muito interessante a sua intervençáo oportuna, com esclarecimentos e explicaçôes pertinentes sobre a história, as paisagens e a organização do espaço que íamos percorrendo. Era assim o Gama na sua faceta de viajante viciado e experimentado.

Obrigado, António Gama. 